\title{
A comparative study of characteristic features of sweat pores of finger bulbs in individuals
}

\author{
Bhoopesh Kumar Sharma ${ }^{1 *}$, Raeesa Bashir ${ }^{2}$, Mayssa Hachem ${ }^{1}$ and Himanshu Gupta ${ }^{3}$
}

\begin{abstract}
Background: Fingerprints are the impressions left on any material by the volar surface also called finger bulbs of the fingers. As per the law of individuality, each individual has a unique set of tiny raised ridges or friction ridges that have been considered necessary in individualization in forensic work. Friction ridges over their surfaces bear the small openings known as sweat pores. The latter are connected to ducts of sweat glands. These pores are also unique to each individual as per many studies and vary in their shape, size, location, and frequency over the friction ridges. Poroscopy is a method of personal identification in which the characteristics of sweat pores on the friction ridge impression of palmar and plantar surfaces are examined.

The present study aimed to uncover the similarities in the sweat pores present on the friction ridges of an individual in respect to their position 'middle or periphery' and to their frequency per unit length and per unit area.

Materials and methods: A total number of 50 samples were collected randomly from different male individuals (graduate and postgraduate students at Amity University). Rolled fingerprint impressions were collected on $\mathrm{FBI}$ fingerprint cards. The collected samples were then analyzed through a stereo-microscope and photomicrography for the shape, position, and the number of sweat pores on the friction ridges per unit length and per unit area. Besides, the number of pores present on three different fingers 'Thumb, Index, Ring' of an individual were considered for this study.
\end{abstract}

Results: Our results report that no relationship exists between the position and frequency of sweat pores occurring per unit length and per unit area. However, a significant correlation exists between the number of pores per unit length and per unit area of the Thumb and Ring fingers for the middle position. Also, a significant correlation was observed between the number of pores per unit length and per unit area of the Index and Ring fingers for the periphery position.

Conclusions: This study may provide useful information about sweat pores present on friction ridges and their utilization for personal identification up to an extent in the cases where very few ridges will be encountered on the crime scene. These data can further be used in forensic research involving individual identification from poroscopy.

Keywords: Sweat pores, Friction ridges, Poroscopy, Shape, Size, Position of sweat pores, Correlation coefficient

\footnotetext{
* Correspondence: bsharma@amityuniversity.ae

'Department of Forensic Sciences, Amity University Dubai, Dubai, United

Arab Emirates

Full list of author information is available at the end of the article
} 


\section{Background}

Poroscopy is the study of sweat pores present on the friction ridges of palmar and the plantar surface and is a method of personal identification (Bindra et al. 2000). It has proved to be a valuable tool in forensic science (Wilder and Wentworth 1918; Cowger 1983). In 1912, Locard established the use of poroscopy in personal identification. Locard observed the ridge characteristics present on the fingerprint pattern and showed that the sweat pores are permanent, immutable, and individual. These pores are useful to establish the identity or otherwise of individuals when available ridges do not provide sufficient ridge characteristics (Bindra et al. 2000). Locard proposed factors for the analysis of the pores for personal identification. These factors include the number and frequency of pores, the distance between two continuous pores or interspacing, the size, shape, and position of the pores on the ridge (Figs. 1, 2, and 3) (Wilder and Wentworth 1918).

Many pieces of research have focused on studying the characteristic of friction ridge mainly the sweat pores among different sex, ages, and populations (Bindra et al. 2000; Wijerathne 2015; Tafazoli et al. 2013; Nagesh et al. 2011; Preethi et al. 2012). Several studies showed that there is no significant difference in the pore characteristics morphology on the epidermal friction ridges between males and females and that the number of pores does not significantly vary.

Several studies have been conducted on palm prints of individuals and sweat pores for their shape, size, position, interspacing, and number per unit area. Findings showed that the identification of an individual with the help of poroscopy was as

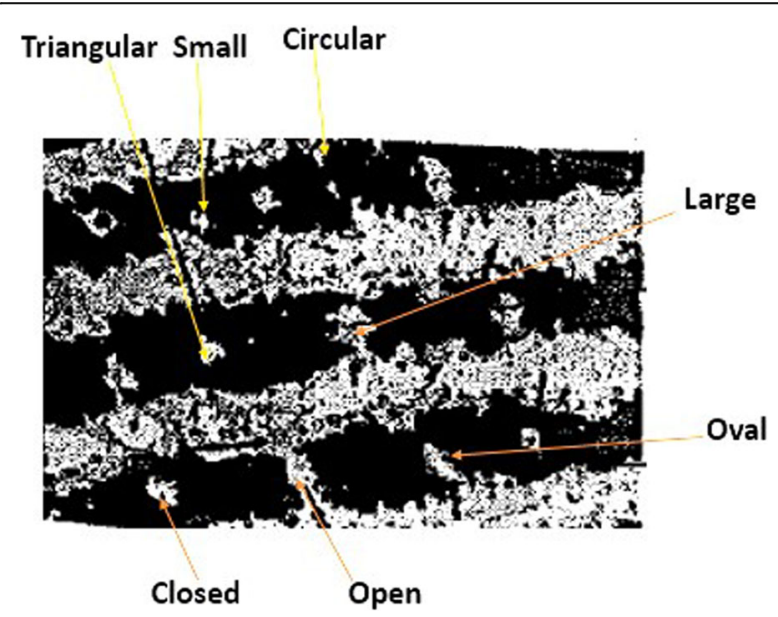

Fig. 1 The picture taken through stereo-microscope using a digital micro camera showing individual types of pores in a rolled impression of an individual on the flowing friction ridge of an individual reliable and accurate as ridge characteristics and can be compared with the results obtained through the study of ridge characteristics (Bindra et al. 2000). Poroscopy was also used as a valuable tool in anthropological studies in forensic science and considered as an essential component in the modern automated fingerprint recognition system. Poroscopy is the third level detail of the friction ridges and therefore, felt more accurate and reliable (Wijerathne 2015). Tafazoli et al. (2013) examined the biological variability of sweat pores in the fingerprints of a sample of the Fars family from the Iranian population. Size, number, position, and relative distance of the sweat pores on the fingers and toes for 20-year-old Iranian males from the Fars family. Their findings showed morphological variety within the sweat pores of the Fars family of the Iranian population. All mentioned studies provide evidence to support the fact that poroscopy as an essential tool in individual identification. Also, several studies have focused on the association of different medical diseases with characteristics of pores helping in the early prediction of later disease occurrence in high-risk individuals (Khosravi et al. 2011).

The main objective of the present study was to focus on the similarities among the sweat pores present on the friction ridges of the fingers of an individual and to make out the significance of the position and frequency of the pores in relation to each other.

\section{Materials and methods}

A total number of 50 samples from different male individuals (graduate and postgraduate students at Amity University) were collected randomly. Rolled fingerprint impressions were collected on FBI fingerprint cards with the black fingerprint ink using ink slab and roller with all appropriate precautions to get the more delicate details of the friction ridges.

The collected samples were analyzed through a stereo-microscope and photomicrography. The study was done for their shape, position, and number of sweat pores on the friction ridges per unit length and per unit area using a micrometer under stereoscopic microscope and with imaging technology (Vision Engineering CamZ) which was artificially illuminated under $7 \mathrm{X}$ and $14 \mathrm{X}$ magnification and then a photomicrograph was taken for further indepth study of pores shape, size, and position. The analysis was conducted by counting the number of pores per unit length, and per unit area, a mark of $0.25 \mathrm{~cm}^{2}$ was taken on the pattern area. A photomicrograph of the field of view (specimen view) was 


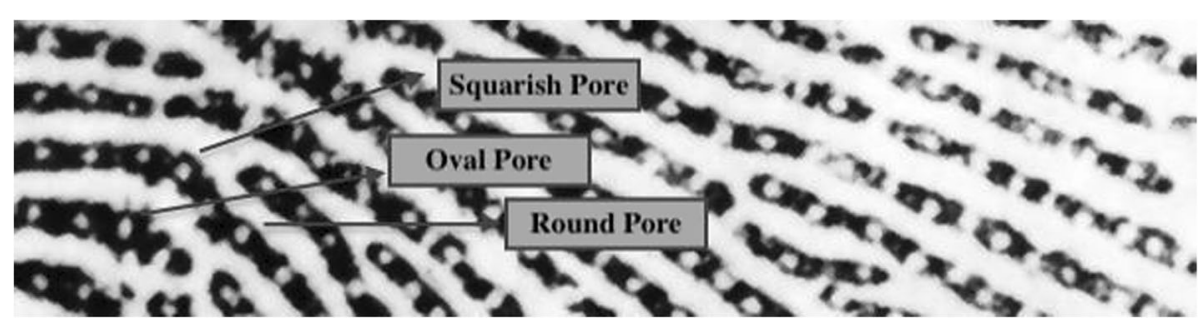

Fig. 2 The photomicrographic image of rolled friction ridge impressions showing different shapes of the sweat pores present on an individuals friction ridges

taken with the help of a digital camera and CamZ magnifier.

\section{Statistical analysis}

Correlation coefficient was computed. The next step was to find the extent to which it is dependable. Probable error of correlation coefficient denoted by P.E(r) was used for testing the reliability of an observed value of correlation coefficient.

If $r$ is the observed correlation coefficient in a sample of $n$ pairs of observations, then its standard error is denoted by $S . E(r)$ is given as shown in below equation:

$$
S . E(r)=\frac{1-r^{2}}{\sqrt{n}}
$$

Probable error of the correlation coefficient is given by the equation:

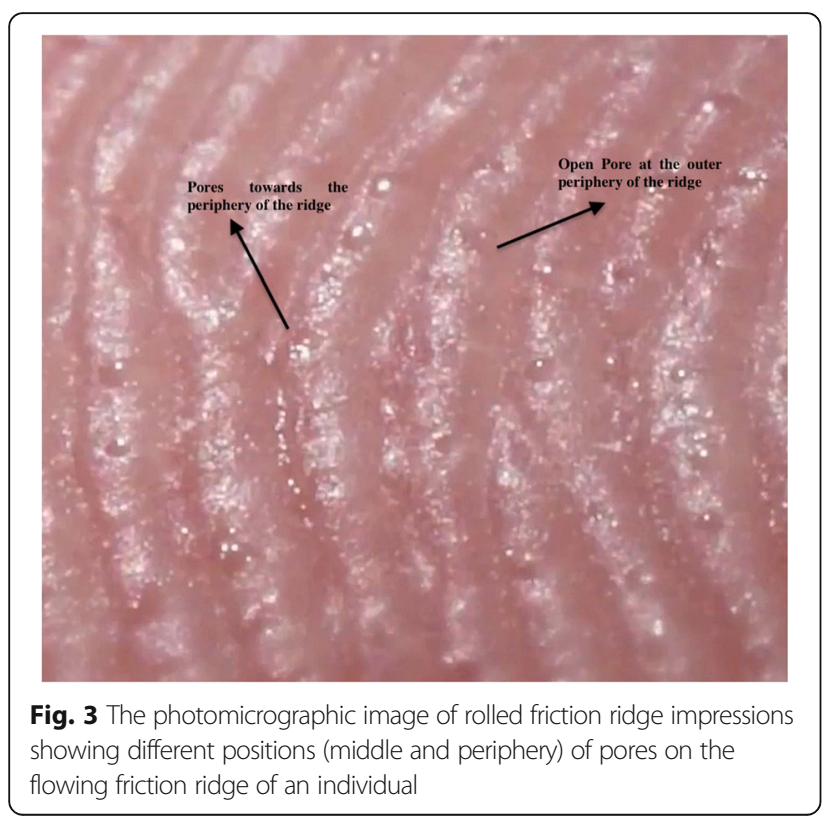

$$
\text { P.E }(r)=0.6745 \times S . E(r)
$$

P.E(r) is used to test if an observed value of sample correlation coefficient is significant of any correlation in the population. If observed value of $r$ is less than 6 $P . E(r)$, then correlation is not at all significant. However, if observed value of $r$ is greater than 6 P.E( $r)$, then correlation is definitely significant.

\section{Results}

Fifty samples were analyzed to determine the similarities in the pores in respect to their position (middle or periphery) on the particular ridge and the frequency (per unit length and per unit area) on the friction ridges of the three different fingers (Thumb, Index, and Ring) of each individual. In addition, the number of pores per unit length and per unit area present on the same three fingers were determined. Initially, the frequency of the position of the pores for the thumb, index, and ring was analyzed. The positions were divided into middle and periphery shown below in tables.

We know that an observed value of $r$ is significant if,

$$
\begin{aligned}
& r>6 \text { P.E }(r) \text { which implies } \frac{r}{P . E(r)}>6 \\
& \text { S.E }(r)=\frac{1-r^{2}}{\sqrt{n}} \\
& \text { P.E }(r)=0.6745 \times \operatorname{S.E}(r)
\end{aligned}
$$

Table 1 Correlation between Thumb, Index, and Ring finger per unit length for middle position

\begin{tabular}{llll}
\hline Correlation & Thumb & Index finger & Ring finger \\
\hline Per unit length, middle position & & \\
Thumb & 1 & 0.416 & 0.673 \\
Index finger & 0.416 & 1 & 0.368 \\
Ring finger & 0.673 & 0.368 & 1 \\
\hline
\end{tabular}


Table 2 Significance of correlation between Thumb, Index, and Ring finger per unit length for middle position

\begin{tabular}{llllll}
\hline $\begin{array}{l}\text { Number of } \\
\text { observations }\end{array}$ & $r$ & $\begin{array}{l}\text { S.E } \\
(r)=\frac{1-r^{2}}{\sqrt{n}}\end{array}$ & $\begin{array}{l}P . E(r)= \\
0.6745 \times S . E(r)\end{array}$ & $\frac{r}{P . E(r)}$ & $\begin{array}{l}\text { Significance } \\
\text { of } r\end{array}$ \\
\hline 50 & 0.42 & 0.126 & 0.078 & $5.38<6$ & $\begin{array}{l}\text { Not } \\
\text { significant }\end{array}$ \\
50 & 0.67 & 0.077 & 0.052 & $12.88>6$ & $\begin{array}{l}\text { Significant } \\
50\end{array}$ \\
0.37 & 0.122 & 0.082 & $3.03<6$ & $\begin{array}{l}\text { Not } \\
\text { significant }\end{array}$ \\
\hline
\end{tabular}

Table 1 shows the correlation between the three different fingers of interest (Thumb, Index, and Ring finger) for middle position per unit length. Whereas Table 2 illustrates the significance of these correlation.

Tables 3 and 4 shows respectively the correlation and the significance of these correlation between Thumb, Index, and Ring finger for periphery position per unit length.

Tables 5 and 6 illustrate respectively the correlation and the significance of these correlation between Thumb, Index, and Ring finger for middle position per unit area.

Table 7 shows the correlation between the three different fingers of interest (Thumb, Index, and Ring finger) for periphery position per unit area. Whereas Table 8 illustrates the significance of these correlation.

\section{Discussion}

The primary purpose of this study was to analyze the sweat pore features in context to their position and frequency in inked impressions through the microscopic and photomicrographic techniques and to provide their linkage per unit length and per unit area in an individual's finger bulbs in Thumb, Index, and Ring fingers. As mentioned previously, the science of poroscopy is based on the fact that the pores are permanent, immutable, and variable from one individual to another in size, shape, position, and number (Locard 1912). Keeping in mind the nature, permanency, immutability, and variability of sweat pores, poroscopy will be a possible mean of personal identification in several cases where

Table 3 Correlation between Thumb, Index, and Ring finger per unit length for periphery position

\begin{tabular}{lcll}
\hline Correlation & Thumb & Index finger & Ring finger \\
\hline Per unit length (periphery) & 1 & -0.091 & \\
Thumb & -0.091 & 1 & -0.074 \\
Index finger & -0.074 & 0.465 & 0.465 \\
Ring finger & & 1 \\
\hline
\end{tabular}

Table 4 Significance of correlation between Thumb, Index, and Ring finger per unit length for periphery position

\begin{tabular}{|c|c|c|c|c|c|}
\hline $\begin{array}{l}\text { Number of } \\
\text { observations }\end{array}$ & $R$ & $\begin{array}{l}S . E \\
(r)= \\
\frac{1-r^{2}}{\sqrt{n}}\end{array}$ & $\begin{array}{l}P . E(r)= \\
0.6745 \times S . E(r)\end{array}$ & $\frac{r}{P . E(r)}$ & $\begin{array}{l}\text { Significance } \\
\text { of } r\end{array}$ \\
\hline 50 & $\overline{-}-09$ & 0.129 & 0.087 & $\begin{array}{l}- \\
1.0399< \\
6\end{array}$ & $\begin{array}{l}\text { Not } \\
\text { significant }\end{array}$ \\
\hline 50 & $\begin{array}{l}- \\
0.07\end{array}$ & 0.140 & 0.094 & $\begin{array}{l}- \\
0.780<6\end{array}$ & $\begin{array}{l}\text { Not } \\
\text { significant }\end{array}$ \\
\hline 50 & 0.46 & 0.110 & 0.0748 & $6.21>6$ & Significant \\
\hline
\end{tabular}

complete or adequate friction ridge impression is missing on the crime scene or such cases. Previously, several studies have been performed to verify such a correlation between sweat pores and different fingers (Preethi et al. 2012). In their research, they have estimated the importance of poroscopy for the identification of individuals and to determine the gender based on frequency, type, and shape of pores. Bindra et al. 2000 have studied the microscopic nature of sweat pores and expressed that it is somewhat difficult as compared to the study of ridge characteristics; however, the identification with the help of poroscopy is as reliable and accurate as ridge characteristics and can be compared with the results obtained through the study of ridge characteristics. Nevertheless, the success or failure of the identification may depend upon many factors such as the amount of pressure applied while transferring the fingerprint impressions, deposition of an amount of sweat, ink or any other material, dirt on friction ridge skin surface, any cuts, or scars. In addition to this, several other external factors that may vary pore dimensions are the type of surface on which the impressions are created, the consistency of ink, etc. (Czarnecki 1995). In the present study, we focused on studying the similarities among the sweat pores present on the friction ridges of three fingers: Thumb, Index, and Ring finger depending on the position (middle, periphery), per unit length and per unit area. When looking to the correlation and their significance between the three fingers per unit length for the middle position (Tables 1 and 2), no significant difference was observed between Thumb and

Table 5 Correlation between Thumb, Index, and Ring finger per unit area for middle position

\begin{tabular}{|c|c|c|c|}
\hline Correlation & Thumb & Index finger & Ring finger \\
\hline \multicolumn{4}{|c|}{ Per unit length (middle) } \\
\hline Thumb & 1 & 0.452 & 0.189 \\
\hline Index finger & 0.452 & 1 & 0.0145 \\
\hline Ring finger & 0.189 & 0.0145 & 1 \\
\hline
\end{tabular}


Table 6 Significance of correlation between Thumb, Index, and Ring finger per unit area for middle position

\begin{tabular}{lcllll}
\hline $\begin{array}{l}\text { Number of } \\
\text { observations }\end{array}$ & $r$ & $\begin{array}{l}\text { S.E } \\
(r)=\frac{1-r^{2}}{\sqrt{n}}\end{array}$ & $\begin{array}{l}P . E(r)= \\
0.6745 \times S . E(r)\end{array}$ & $\frac{r}{P . E(r)}$ & $\begin{array}{l}\text { Significance } \\
\text { of } r\end{array}$ \\
\hline 50 & 0.45 & 0.112 & 0.076 & $5.92<6$ & $\begin{array}{l}\text { Not } \\
\text { significant }\end{array}$ \\
50 & 0.19 & 0.136 & 0.009 & $20.67>6$ & $\begin{array}{l}\text { Significant } \\
50\end{array}$ \\
0.01 & 0.141 & 0.095 & $0.07<6$ & $\begin{array}{l}\text { Not } \\
\text { significant }\end{array}$ \\
\hline
\end{tabular}

Index, and between Index and Ring finger. However, a significant difference was noted between the Thumb and Ring finger.

When studying the correlation between the three fingers for periphery position, per unit length (Tables 3 and 4), no significant correlation existed between Thumb and Index, Thumb and Ring.

But, a significant one was detected between Index and Ring finger.

These results were confirmed when examining the correlations between Thumb, Index, and Ring fingers for the middle position (Tables 5 and 6) per unit area and periphery position (Tables 7 and 8) per unit area.

\section{Conclusions}

The present study was conducted to find out the similarities in the pores in respect to the position (middle or periphery) and frequency (per unit length and per unit area) of the pores present on the friction ridges of the finger of an individual. The hypothesis considered was that there is no significant relationship between the position of the pores and their occurrence per unit length and per unit area. After analyzing the significance of correlation, it was seen that no relationship exists generally between the position and frequency of sweat pores occurring per unit length and per unit area. However, a significant correlation exists between the number of pores per unit length and per unit area of the Thumb and Ring fingers (middle). Also, it was observed that there is significant relation

Table 7 Correlation between Thumb, Index, and Ring finger per unit area for periphery position

\begin{tabular}{lcll}
\hline Correlation & Thumb & Index finger & Ring finger \\
\hline Per unit length (periphery) & & \\
Thumb & 1 & -0.075 & -0.023 \\
Index finger & -0.075 & 1 & 0.703 \\
Ring finger & -0.023 & 0.703 & 1 \\
\hline
\end{tabular}

Table 8 Significance of correlation between Thumb, Index, and Ring finger per unit area for periphery position

\begin{tabular}{|c|c|c|c|c|c|}
\hline $\begin{array}{l}\text { Number of } \\
\text { observations }\end{array}$ & $r$ & $\begin{array}{l}S . E \\
(r)=\frac{1-r^{2}}{\sqrt{n}}\end{array}$ & $\begin{array}{l}P . E(r)= \\
0.6745 \times S . E \\
(r)\end{array}$ & $\frac{r}{P . E(r)}$ & $\begin{array}{l}\text { Significance } \\
\text { of } r\end{array}$ \\
\hline 50 & $\begin{array}{l}- \\
0.08\end{array}$ & 0.140 & 0.094 & $\begin{array}{l}- \\
0.791< \\
6\end{array}$ & $\begin{array}{l}\text { Not } \\
\text { significant }\end{array}$ \\
\hline 50 & $\overline{-}-023$ & 0.141 & 0.095 & $\begin{array}{l}- \\
0.241< \\
6\end{array}$ & $\begin{array}{l}\text { Not } \\
\text { significant }\end{array}$ \\
\hline 50 & 0.703 & 0.072 & 0.048 & $14.58>6$ & Significant \\
\hline
\end{tabular}

between the number of pores per unit length and per unit area of the Index and Ring fingers (periphery). It is clear that the scientific study of these critical minute anatomical structures might open doors to many scientific discoveries in the fields of forensic science and individual identification.

\section{Abbreviations \\ FBI: Federal Bureau of Investigation; Fig: Figure; N: Number of samples; $P$ value: Probability of the occurrence; SEM: Standard error of the mean}

\section{Acknowledgements}

I am thankful to Dr. Vajahat Hussain (CEO Amity Middle East), Dr. N. Ramachandran (Pro. VC Amity University Dubai), and Dr. S K Shukla (Director, Amity Institute of Forensic Sciences, AUUP) to provide the appropriate equipment and samples for the support of this project.

\section{Authors' contributions}

BKS: Main author of the article and supervisor of the project to the student. RB: Assistant Professor, Mathematics, Amity University Dubai. Co-author and statistical analyst for the current study. MH: Assistant Professor, Forensic Science at Amity University Dubai. Co-author and assisted in the collection of the data. HG: Masters of Forensic Science at Amity University who had undergone this project under BKS guidance. All authors read and approved the final manuscript.

Funding

By Amity University Dubai.

\section{Availability of data and materials}

The datasets generated and/or analyzed during the current study are available in the Amity University, Forensic Laboratory and can be presented in case required.

\section{Ethics approval and consent to participate}

In the present research, the samples of fingerprints from the students of Amity University were collected as a part of their assignment and project. The consent was obtained accordingly. No animal data has been included in the study.

\section{Consent for publication}

Not applicable in the current research as all the experiments have been studied in Amity University as the curriculum requirement of the students projects and I as the programme head bears this responsibility. The consents of the authors have been obtained.

\section{Competing interests}

The project has been completed in Amity University Dubai and have no objection in the publication of the same. The authors have no competing interest. 


\section{Author details}

'Department of Forensic Sciences, Amity University Dubai, Dubai, United Arab Emirates. ${ }^{2}$ Mathematics Amity University Dubai, Dubai, United Arab Emirates. ${ }^{3}$ Forensic Science, Amity University Uttar Pradesh (India), Noida, India.

Received: 27 November 2018 Accepted: 26 June 2019

Published online: 25 July 2019

\section{References}

Bindra, B, Jasuja OP, Singla AK (2000) Poroscopy: A method of personal identification revisited. Aggrawal's Internet J Forensic Med Toxicol 1(1). https://www.anilaggrawal.com/ij/vol_001_no_001/paper003.html. Accessed 11 July 2019.

Cowger JF (1983) Friction ridge skin: comparison and identification of fingerprints. Elsevier Science Publishing, New York

Czarnecki, E., 1995 "Poroscopy: an overview". Available at http://www.scafo.org/ library/110401.html. Last accessed on 14 Mar 2019

Khosravi A, Behnam Rassouli M, Mahdavi Shahri N, Dadgar AA, Ejtehadi H (2011) An investigation of the palmar distribution of sweat glands pores in women with hypertension in Khorasan province. Arak Med Univ J 14:19-26

Locard E (1912) Les pores et l'identification des criminels. Biol - J Scientifique Dumédecin 2(24):357-365

Nagesh KR et al (2011) A preliminary study of pores on epidermal ridges: are there any sex differences and age related changes? J Forensic Legal Med 18(7):302-305

Preethi D, Nithin M, Manjunatha B, Balaraj B (2012) Study of poroscopy among south Indian population*. J Forensic Sci 57(2):449-452

Tafazoli M, Mahdavi Shahri N, Ejtehadi H, Haddad F, Jabbari Nooghabi H, Mahdavi Shahri M, Naderi S (2013) Biological variability of sweat gland pores in the fingerprints of a Fars Iranian family from Khorasan Razavi Province. Iran Anat Sci J 10(2):99-104

Wijerathne B (2015) Poroscopy: an important research field in medicine and physical anthropology. Anuradhapura Med J 9(2):44

Wilder HH, Wentworth B (1918) Personal Identification. The Gorham Press, Boston

\section{Publisher's Note}

Springer Nature remains neutral with regard to jurisdictional claims in published maps and institutional affiliations.

\section{Submit your manuscript to a SpringerOpen ${ }^{\circ}$ journal and benefit from:}

- Convenient online submission

- Rigorous peer review

- Open access: articles freely available online

- High visibility within the field

- Retaining the copyright to your article

Submit your next manuscript at $\boldsymbol{\nabla}$ springeropen.com 